\title{
Impacts of Chromium from Tannery Effluent and Evaluation of Alternative Treatment Options
}

\author{
Alebel Abebe Belay \\ School of Environmental health, Jimma University, Jimma, Ethiopia. \\ Email: alebelab@yahoo.com \\ Received December $25^{\text {th }}, 2009$; revised February $2^{\text {nd }}, 2010$; accepted February $3^{\text {rd }}, 2010$.
}

\begin{abstract}
The paper has focused on the challenges/impacts of tannery effluent and evaluates the alternative treatment options used to treat, recover or recycle chromium from the waste water. The paper was done entirely on secondary data by consulting literature sources including scientific journals, chapters of books, conference report papers and websites. The results of this review paper indicated that chromium is highly toxic and carcinogenic to human beings, animals, plants and the general environment (soil and water sediment). It is found out that chrome is the primary threat when ever tanning industry comes in to practice. Though many treatment options were evaluated to prevent its consequence on the environment, neither of them could achieve to treat or recover chrome $100 \%$. Treatment options are either; inefficient, complicated, energy demanding, costly or applicable to a certain parts of the world due to technology or skilled man power demand. Therefore, to tackle this serious challenge stringent environmental regulation with law enforcement has to be exercised to use better treatment system which is widely applicable. Polluters must also know the environmental cost of their industry and treated according to polluter pay or precautionary principles. Moreover, the general public has to be aware of it and all concerned organizations and governments has to work hand in hand to reach zero discharge level or at least to attain the EPA chrome discharge limit.
\end{abstract}

Keywords: Chromium Toxicity, Environmental Impact, Chromium Recovery and Recycling, Chromium Treatment Option, Tannery Effluent

\section{Introduction}

All sectors of our society generate waste: industry, agriculture, mining, energy, transportation, construction and consumers. Waste contains pollutants which are discarded materials, process materials or chemicals. Pollution could be caused by these pollutants when they are released beyond the assimilation capacity of the environment. Industrial wastes are generated from different processes and the amount and toxicity of waste released varies with its own specific industrial processes [1]. Tannery effluents are ranked as the highest pollutants among all industrial wastes. They are especially large contributors of chromium pollution. For instance, in India alone about 2000-3000 tone of chromium escapes into the environment annually from tannery industries, with chromium concentrations ranging between 2000 and 5000 $\mathrm{mg} / \mathrm{l}$ in the aqueous effluent compared to the recommended permissible discharge limits of $2 \mathrm{mg} / \mathrm{l}$ [2].

There are two types of tanning systems which are vegetable tanning, which does not contain chromium, and chrome tanning. However, due to the high pollution load and low treatability, conventional vegetable tanning can't be considered more environmentally friendly than chrome tanning. Moreover, vegetable tanned leathers have different physical properties and specific applications, but is biodegradable [3]. Currently more than $90 \%$ of global leather production of 18 billion sq. $\mathrm{ft}$ is through chrome-tanning process [4]. Chromium salts (particularly chromium sulphate) are the most widely used tanning substances today. Hides tanned with chromium salts have a good mechanical resistance, an extraordinary dyeing suitability and a better hydrothermic resistance in comparison with hides treated with vegetable substances. Unfortunately only a fraction of the chromium salts used in the tanning process react with the skins. The rest of the salts remain in the tanning exhaust bath and are subsequently sent to a depuration plant where the chromium salts end up in the sludge [5]. One of the major emerging environmental problems in the tanning industry is the disposal of chromium contaminated sludge produced as a by-product of wastewater treatment. Tannery effluents severely affect the mitotic process and reduce seed germination in extensively cultivated pulse crops [2].

At high concentrations chromium is toxic, mutagenic, carcinogenic, and teratogenic. Chromium exists in oxida- 
tion states of $+2,+3$, and +6 . The trivalent oxidation state is the most stable form of chromium and is essential to mammals in trace concentration and relatively immobile in the aquatic system due to its low water solubility. The hexavalent chromium is much more toxic to many plants, animals, and bacteria inhabiting aquatic environments. Most micro-organisms are sensitive to $\mathrm{Cr}$ (VI) toxicity but some groups possess resistance mechanisms to tolerate high levels. A relationship was found between the total chromium content of soil and the presence of metal tolerant/resistant bacteria [2]. In natural waters two stable oxidation states of $\mathrm{Cr}$ persist (III and VI), which have contrasting toxicities, motilities, and bioavailability. $\mathrm{Cr}$ (VI) is motile and highly toxic and soluble in water and it is a strong oxidizing agent that causes severe damage to cell membranes [6].

Worldwide chromium contamination of soils has arisen predominantly from the common practice of land-based disposal of tannery wastes under the assumption that the dominant species in the tannery waste would be the thermodynamically stable Cr (III) species. However, recent detection of significant levels of toxic $\mathrm{Cr}$ (VI) in surface water and groundwater in different part of the world raise critical questions relating to current disposal of Cr-containing wastes. Despite the thermodynamic stability of $\mathrm{Cr}$ (III), the presence of certain naturally occurring minerals, especially $\mathrm{MnO}_{2}$ oxides, can enhance oxidation of $\mathrm{Cr}$ (III) to $\mathrm{Cr}$ (VI) in the soil environment. This factor is of public concern because at high $\mathrm{pH}, \mathrm{Cr}$ (VI) is bio available, and it is this form that is highly mobile and therefore poses the greatest risk of groundwater contamination [7].

Cleaner technologies used to reduce chromium in waste water such as high exhaustion process, direct or indirect chromium recycling cannot eliminate completely from effluent coming from post tanning section. In response to this challenge, replacement of chromium with combinations of metallic cat ions, for example titanium, magnesium, aluminium and zirconium, was tried but the results obtained at the moment are not completely satisfying for all types of leather. Synthetic organic tanning agents, alone or in combination with a metallic cat ion can be considered as a substitute for chromium in some types of leather, provided that environmental and workers health regulations are complied with [3].

Although Cr III is an essential nutrient for human beings, there is no doubt that $\mathrm{Cr}$ (VI) compounds are both acutely and chronically toxic. The dose threshold effect for this element has not yet been determined accurately enough to allow regulations to be defined. However some risk assessment analysis is currently being undertaken. Cr III is less toxic than some other elements $(\mathrm{Hg}$, $\mathrm{Cd}, \mathrm{Pb}, \mathrm{Ni}$ and $\mathrm{Zn}$ ) to mammalian and aquatic organism, probably due to the low solubility of this element in its trivalent form. Cr III compounds also have a very low mobility in soils and are thus relatively unavailable to plants [ibid]. The direct discharge of effluents from tanneries in to water bodies has become a growing environmental problem in these days. Most of these waste waters are extremely complex mixtures containing inorganic and organic compounds that make the tanning industry potentially a pollution-intensive sector [8].

In general chrome waste from leather processing poses a significant disposal problem to human health and the environment. Today, all tanneries must thoroughly check their waste streams. Chrome discharge into those streams is one of the components that have to be strictly controlled. The environmental impact of chrome waste from tanneries has been a subject of extensive scientific and technical dispute. Statutory limits have since been set for chrome discharge and disposal, and relevant guidelines have been drawn up throughout the world. Due to high correlation between chrome tanning and its environmental impact, checking of the efficiency of processing operations and treatment plant takes on prime importance. Therefore, the objective of this paper is to describe potential impact of tannery waste, evaluate the different chrome treatment methods and to discuss the challenges faced to chrome removal technologies.

\section{Chromium Toxicity and its Accumulation}

Industrial activities like electro plating, metal cleaning and dyeing processing, cement, and leather tanning are the major sectors that play role in releasing chromium into the environment. Chrome in the hexa-valent form is very toxic. It is quite intriguing that contaminated field by industrial effluent show a mobilization ration of less than 5 (potentially toxic) for selected plant specious. Surprisingly, the mobilization ratios for weeds become greater than 5 , which have healthy morphology in the early flowering stage [9].

A study done by Marchese et al, 2008 about the rate of accumulation of chromium in four fresh water plant species, clams, crabs, and fishes showed that, all the four fresh water species and animals were found with high concentration of chromium which is an indication of its high accumulation potential. This clearly indicates that this problem become more serious and toxic to human beings which are found at the top of the food web due to its toxicity and bio accumulation effect.

In the tanning industry leather processing involves conversion of put rescible hide or skin into leather. Tanning agents could help permanent stabilization of the skin matrix against biodegradation. This industry has gained a negative image in society with respect to its pollution potential and therefore is facing a severe challenge. The unit processes that cause tanneries the most difficult with regard to perceived environmental impact are unharing and chrome tanning. Basic chromium sulfate (BCS) is a tanning agent, which is employed by $90 \%$ 
of the tanning industry. Conventional chrome tanning results in wastewater containing as high as 1500-3000 ppm (parts per million) of chromium; however, the present day high-exhaust chrome tanning methods lead to a wastewater containing 500-1000 ppm of chromium [10]. But, the discharge limits for trivalent chromium vary broadly ranging from 1 to $5 \mathrm{mg} / 1$ in the case of direct discharge into water bodies and 1 to $20 \mathrm{mg} / \mathrm{l}$ in the case of discharge into the public sewer system. Therefore, the treatment plant used by the tanning industry needs to treat the influent by 200 fold to send to water bodies, which is not practical in most of the cases [11].

\section{Chrome Recovery and Recycling}

Conventional chrome tanning in leather production produces spent liquors containing significant amounts of chromium and other polluting substances, both organic and inorganic. From the total chromium used for tanning only $60 \%$ to $70 \%$ is utilized, while the rest 30 to $40 \%$ remains in the spent tanning liquor, which is normally sent to a wastewater treatment plant. This inefficient use of chromium and its release to the environment has to be compensated by designing a good recovery and recycling scheme. The recovery of chromium from spent tanning and re-tanning baths provides a significant economic advantage in terms of both its reuse and the simplification of the processing of global wastewaters [12].

Several recovery techniques such as chemical precipitation, membrane processes, adsorption, redox adsorption, and ion exchange have been proposed for this purpose. Among these membrane process offer very interesting opportunities for the recovery and recycling of primary resources from spent liquors of unit operations such as soaking, unhairing, degreasing, pickling, dyeing, and chromium tannage. Studies showed that the application of nanofiltration (NF) and reverse osmosis (RO) in combination can provide better recovery of unreacted chromium from high concentrated spent tanning effluent. However, this technique is being challenged by the presence of considerable biological oxygen demand (BOD) and proteins, which can cause fouling and subsequent system failure, either temporarily or permanently [12].

In practice, there are two ways of chrome recycling methods which are widely practiced: these are direct and indirect recycling. The direct form entails spent float being recycled direct to the chrome tanning processing for re-use. While, the indirect form entails precipitating and separating the chrome from the float containing residual chrome, and then re-dissolving it in acid for re-use. The efficiency of both methods can be very high (more than $90 \%$ ); it depends on the effectiveness of the float collection process and the recycling/reusing technique. Of the two approaches, chrome recovery is more widely used than chrome precipitation. However, it is mandatory to adopt and practice the new technologies which are more efficient in recovering this chemical, which is a big challenge to tanning industry [13].

Use of chemical compounds for chrome treatment is not a new phenomenon. A study conducted by M. ali awan et al., 2003 identified three aqueous oxidants, namely; Hydrogen peroxide, Sodium Hypochlorite and Calcium Hypochlorite independently in oxidizing Chromium (III) containing tannery wastewaters to soluble chromate $\left(\mathrm{CrO}_{4}{ }^{2-}\right)$ under alkaline conditions. Among those, Hydrogen peroxide was potentially a suitable oxidant as it could recover chromate $\left(\mathrm{CrO}_{4}{ }^{2-}\right)$ up to $98 \%$ (from synthetic $\mathrm{Cr}^{3+}$ solution) and $88 \%$ (from effluent I). Despite the different experimental conditions (temperatures and oxidation time) for all the three oxidants complete $(100 \%)$ recovery could not be achieved. The recovery of chromium could help in reducing the possibility of oxidizing Cr III to Cr VI (carcinogenic) compound and helps to rescue the financial and environmental cost occurred as a result of its discharge [14]. Other kinds of methods like combined system have to be also tested since it might improve the efficiency of recovering chromium from tanning process. In fact experimental conditions like, temperature, $\mathrm{PH}$, time, need to be controlled to have more efficient recovery.

\section{Treatment Medias Used for Chromium Removal}

A wide range of physical and chemical processes are available for the removal of $\mathrm{Cr}$ (VI) from effluents. A major drawback with those treatment systems is sludge production, and, high operational cost and some of them are complicated for management. This actually makes the application of these technologies to be limited only in developed countries. In response to this challenge a different attempt were undertaken to produce a media which was feasible and cost effective to use by the majority. A research was done S. M. Nomanbhay and K. Palanisamy, 2005 by preparing a new composite bio sorbent which has been done by coating chitosan onto acid treated oil palm shell charcoal (CCAB). It is an attractive option because of its cost effective treatment system. Among other low cost absorbent identified chitosan has the highest sorption capacity for several metal ions including Chrome. Chromium adsorption was influenced by initial $\mathrm{PH}$, agitation, dose of adsorbent and contact time. For instance at a PH of 5 the media managed to treat $92 \%$ of chromium, which is significant. Further control of these environmental conditions in the laboratory may improve its treatment capacity [15].

A comparison study also conducted by leaching raw tannery effluent through mono and mixed columns (different grades) of vermiculite to evaluate their removal efficiency of chromium. The mixed column of vermiculite has the highest chromium removal $(74.6 \%)$ while the 
mono vermiculite achieved $63.6 \%$. This improvement in chrome removal efficiency is brought by the use of combined medias which increase its adsorption capacity. It was also found out that, it could remove cat ions like $\mathrm{Ca}$, $\mathrm{Na}, \mathrm{Mg}$ and $\mathrm{K}$. of course high cat ion exchange helps to make the system more efficient [16].

Recently different studies are concentrating use of combined medias under the control of laboratory environment and the results seem promising. A research has been done in Ethiopia by Tadesse et al, 2005 to check the removal efficiency of chromium from tannery effluent in a horizontal settling tanks and subsequent Advanced Integrated Wastewater Pond System (AIWPS) reactors. The raw combined effluent from the tannery had a different $\mathrm{PH}$ and its removal efficiency was measured in detention time and $\mathrm{PH}$ to come up with the best chrome removal efficacy. After a one day detention time $58-95 \%$ of trivalent chromium has been removed in the primary settling tank when the $\mathrm{PH}$ is approached to 8 , which is the optimum precipitation $\mathrm{PH}$ for trivalent chromium.

A significant amount of chromium has also removed in the secondary facultative pond and maturation pond. The presence of sulphide plays a role in the overall removal of chromium. It has some coagulating effect besides maintaining a conducive $\mathrm{pH}$ for the formation of $\mathrm{Cr}$ $(\mathrm{OH})_{3}$ precipitate. However, since chromium doesn't make any stable precipitate with sulphide, it has no any effect in the chromium removal chemically. With $\mathrm{Cr}$ (III) concentration of $0.2-0.8 \mathrm{mg} / \mathrm{l}$ in the final treated effluent, the AIWPS preceded by horizontal settling tanks produced effluent that could easily meet most of the current $\mathrm{Cr}$ (III) discharge limits. This study is prominent in finding ways to achieve the maximum removal of chromium and producing an effluent that meet the standard criteria to discharge to water bodies. This technique needs get attention to be considered and applied in the conventional tannery treatment system to improve its efficiency and prevent the alleged environmental consequence due to the toxic effluent discharge [11].

The ever increasing concern about the deterioration of the environmental condition could be a driving force to assess and remediate pollutant from the ecosystem. On this regard the use of plant species especially algae become acknowledged in indicating and managing metal pollution. Despite the fact that a large scale study and experience has been developed in different countries to use algal ponds as effective means of sewage treatment system the accumulation potential of algal species and seasonal variation of tolerance is not exhaustively addressed. Rai et al., 2005 did a study on seasonal variation of algal growth in tannery effluent and metal accumulation potential for chromium removal scheme. It has been noticed that different algal species found with accumulated chromium in their tissue, which could be used in developing bioremediation strategy for pollution abatement. Of course, factors like population density, volume of effluent, the nature of mixing with effluent and optimum algal biomass should be considered and well examined before promoting for wide application [17].

Wastewater characterization is an important step in designing effective treatment facilities for industrial wastewaters. This is especially true for tanneries which exhibit significant differences in their production processes that generate effluents of unique and complex nature. Characterization is also needed for assessing the performance of individual unit operations and processes. Most pollutants in wastewaters appear to exist either in particulate form or are associated with particulates. This understanding led to the wastewater treatment strategy of removing particulate and colloidal matter in the primary step using suitable coagulants. A study investigated about chemically enhanced primary treatment (CEPT) technology that uses different coagulants for enhanced pollutants removal at the primary stage of the wastewater treatment. Among those coagulants used, alum has been found to be the suitable coagulant for tannery wastewater in a dose range of $200-240 \mathrm{mg} / \mathrm{L}$ as $\mathrm{Al}_{2}\left(\mathrm{SO}_{4}\right)^{3}$ and it has removed $98.7-99.8 \%$ of chromium. The final effluent also met the national effluent quality standards for chromium and total suspended solids. However other COD content needs secondary treatment for the tannery effluent. Therefore, CEPT technique offers almost complete removal of chromium and produces an effluent that will no more affect the receiving water bodies [18].

\section{Process Modification}

Commercial conventional chrome tanning has poor chromium uptake, only about $55-60 \%$ (average). So, constant innovative process modifications for cleaner technology have been of the utmost importance in the leather-processing sector to safeguard our environment. The method employed in the leather processing industry subjects the hides and skins to treatment with a wide variety of chemicals and passage through various unit operations. All this involves an enormous amount of time and they contribute to an increase in chromium, COD, chlorides, sulfates and other mineral salts, which end up as effluent. But, perhaps more alarmingly, the process uses profuse quantities of water in areas where there is rapid depletion of ground water. Very provoking research paper was presented by Mukherjee, 2006 in the international union of leather technologies and chemist societies (IULTCS) Congress to overcome this great challenge. This study explored a process to reduce water usage, vis-a-vis deliming, pickle and basification-free chrome tanning [19].

This leads to a substantial decrease in chemical consumption by $20 \%$ for chrome tanning alone. Consumption of water can be cut by $37-40 \%$. It is also an energy 
efficient technology. This exceptional approach is very appealing to tanning companies, environmentalist and also invites other researchers to do some job for possible improvement or it guides somehow to a new direction. There are some key words frequently used by scientists like pollution prevention, waste minimization, product empowerment and process innovation. However, these approaches are very much confined within recycling of wastewater to a maximum number of cycles followed by discharging or use of environmentally-friendly chemicals. In principle discharge of minimum pollution loads or a zero-discharge concept should be the topic of the day to prevent pollution completely [19].

From this intensive review of literature it is evident that chromium is very toxic to human health, animals and the environments (soil, water, sediments plants and etc). There are many options of treating chromium from tannery effluent and some treatment techniques managed nearly $99 \%$ of removal of chromium from the spent liquor. Usually, these kind of technologies are complicated, expensive, energy intensive, can be applied on a specific region, others need skilled personnel and some technologies not yet commercialised. However, technology like electro coagulation could give very high removal of chromium (98\%) and reproducibility to developing countries due to its low cost. Despite all these scientific attempts tanning industry is still one of the major polluter of the environment worldwide. Therefore, to prevent the public health and environmental impact of tannery waste in general and chromium in particular the environmental regulation like effluent discharge limit has to be stringent and organization should be powerful to the extent to take measure by applying polluter principle or precautionary principle to avoid the effect of toxicity and bioaccumulation.

\section{REFERENCES}

[1] T. T. Shen, "Industrial pollution prevention," $2^{\text {nd }}$ Edition, Springer, pp. 40, 1999.

[2] M. M. Altaf, F. Masood, and A. Malik, "Impact of long-term application of treated tannery effluents on the emergence of resistance traits in rhizobium sp. isolated from trifolium alexandrinum," Turkish Journal of Biology, Vol. 32, pp. 1-8, 2008.

[3] Moore and Ramamoorthy, "IUE assessment for chromium containing waste forms the leather industry," 2001. http:// www.ctc.fr/faq/docs/CTC_recommendations_IUE_3.pdf

[4] V. J. Sundar, J. R. Rao, and C. Muralidharan, "Cleaner chrome tanning - emerging options," Journal of cleaner production, Vol. 10, pp. 69-74, 2002.

[5] B. Wionczyk, W. Apostoluk, and W. A. Charewicz, "Solvent extraction of chromium (III) from spent tanning liquors with Aliquat 336," Journal of Hydrometallurgy, Vol. 82, No. 1-2, pp. 83-92, 2006.
[6] M. Marchese, A. M. Gagneten, M. J. Parma, and P. J. Pavé, "Accumulation and elimination of chromium by freshwater species exposed to spiked sediments," Archives of Environ Contamination and Toxicology, Springer, Vol. 55, No. 1, pp. 603-609, 2008.

[7] S. Avudainayagam, M. Megharaj, G. Owens, R. S. Kookana, D. Chittleborough, and R. Naidu, "Chemistry of chromium in soils with emphasis on tannery waste sites," Review of Environmental Contamination And Toxicology, Springer, Newyork, Vol. 178, pp. 53-91, 2003.

[8] J. C. Akan, E. A Moses, and V. O. Ogugbuaja, "Assessment of tannery industrial effluent from Kano metropolis, Nigeria," Asian Network for Scientific Information, Journal of Applied Science, Vol. 7, No. 19, pp. 2788-2893, 2007.

[9] G. C. Kisku, S. C. Barmanland, and S. K. Bhargava, "Contamination of soil and plants with potentially toxic elements irrigated with mixed industrial effluent and its impact on the environment," Journal of Water, Air, and Soil Pollution Kluwer Academic Publishers, Vol. 120, No. 1-2, pp. 121-137, 1999.

[10] R. Aravindhan, B. Madhan, J. R. Rao, B. U. Nair, and T. Ramasami, "Bioaccumulation of chromium from tannery wastewater: An approach for chrome recovery and reuse," Environmental Science and Technology, American Chemical Society, Vol. 38, No. 1, pp. 300-306, 2004.

[11] I. Tadesse, S. A. Isoaho, F. B. Green, and J. A. Puhakka, "Lime enhanced chromium removal in advanced integrated wastewater pond system, bio resource technology," Elsevier, Vol. 97, No. 4, pp. 529-534, 2006.

[12] A. Cassano, L. D. Pietra, and E. Drioli, "Integrated membrane process for the recovery of chromium salts from tannery effluents," Industrial \& Engineering Chemistry Research, American Chemical Society, Washington, DC, Vol. 26, No. 21, pp. 6825-6830, 2007.

[13] J. Ludvík, "Chrome balance in leather processing, regional programme for pollution control in the tanning industry in south-east Asia," United Nations Industrial Development Organization Report, 2000. Available at: Http:/www.unido. org/fileadmin/user_media/Publications/Pub_free/Chrome_b alance_in_leather_processing.pdf

[14] M. ali awan, M. A. Baig, J. Iqbal, M. R. Aslam, and N. Ijaz, "Recovery of chromium (III) from tannery wastewater," Journal of Applied Sciences and Environmental Management, Bioline International, Vol. 7, No. 2, pp. 5-8. 2003.

[15] S. M. Nomanbhay and K. Palanisamy, "Removal of heavy metal from industrial wastewater using chitosan coated oil palm shell charcoal," Electronic Journal of Biotechnology, Vol. 8, No. 1, 2005.

[16] R. M. Jayabalakrishnan and D. Aselvaseelan, "Efficiency of mono and mixed columns of vermiculites for treating raw tannery effluent," Journal of Applied Science, Asian Network for Scientific Information, Vol. 7, No. 7, pp. 10481052, 2007.

[17] U. N. Rai, S. Dwivedi, R. D. Tripathi, O. P. Shukla, and N. K. Singh, "Algal biomass: An economical method for removal of chromium from tannery effluent," Bulletin of 
Environmental Contamination and Toxicology, NBRI Research Publication, Vol. 75, No. 2, pp. 297-303, 2005.

[18] S. Haydar and J. A. Aziz, "Characterization and treatability studies of tannery wastewater using chemically enhanced primary treatment (CEPT)," A Case Study of Saddiq
Leather Works, Journal of Hazardous Materials, Elsevier, Vol. 163, No. 2-3, pp. 1076-1083, 2007.

[19] G. Mukherjee, "Conventional chrome, leather international technology," 2006. Available at: http://www.Leathermag. com/news/fullstory.php/aid/10454/Conventional_chrome.html 